CRYSTALLOGRAPHIC COMMUNICATIONS

ISSN 2056-9890

Received 9 March 2017

Accepted 16 March 2017

Edited by A. J. Lough, University of Toronto, Canada

Keywords: crystal structure; formamidinium iodide; phase transitions; powder diffraction; synchrotron radiation.

CCDC reference: 1538402

Supporting information: this article has supporting information at journals.iucr.org/e

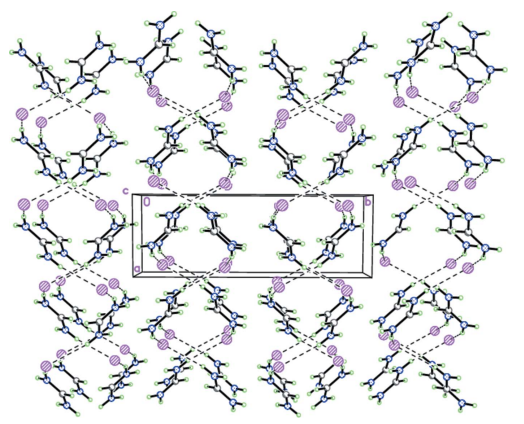

OPEN $\odot$ ACCESS

\section{Formamidinium iodide: crystal structure and phase transitions}

\author{
Andrey A. Petrov, ${ }^{a}$ Eugene A. Goodilin, ${ }^{\text {a,b }}$ Alexey B. Tarasov,,${ }^{a, b *}$ Vladimir A. \\ Lazarenko, ${ }^{\mathrm{c}}$ Pavel V. Dorovatovskii ${ }^{\mathrm{c}}$ and Victor N. Khrustalev ${ }^{\mathrm{d}, \mathrm{e}}$
}

\footnotetext{
aDepartment of Materials Science, Lomonosov Moscow State University, Lenin Hills, 119991 Moscow, Russian Federation, 'bepartment of Chemistry, Lomonosov Moscow State University, Lenin Hills, 119991 Moscow, Russian Federation, 'National Research Centre 'Kurchatov Institute', 1 Acad. Kurchatov Sq., Moscow 123182, Russian Federation, 'dnorganic Chemistry Department, Peoples' Friendship University of Russia (RUDN University), 6 MiklukhoMaklay St., Moscow 117198, Russian Federation, and ${ }^{\mathbf{e} X-R a y ~ S t r u c t u r a l ~ C e n t r e, ~ A . ~ N . ~ N e s m e y a n o v ~ I n s t i t u t e ~ o f ~}$ Organoelement Compounds, Russian Academy of Sciences, 28 Vavilov St., B-334, Moscow 119991, Russian Federation. ${ }^{*}$ Correspondence e-mail: alexey.bor.tarasov@gmail.com
}

At a temperature of $100 \mathrm{~K}, \mathrm{CH}_{5} \mathrm{~N}_{2}{ }^{+} \cdot \mathrm{I}^{-}(\mathbf{I})$, crystallizes in the monoclinic space group $P 2_{1} / c$. The formamidinium cation adopts a planar symmetrical structure [the r.m.s. deviation is $0.002 \AA$, and the $\mathrm{C}-\mathrm{N}$ bond lengths are 1.301 (7) and 1.309 (8) $\AA$ ] . The iodide anion does not lie within the cation plane, but deviates from it by 0.643 (10) $\AA$. The cation and anion of $\mathbf{I}$ form a tight ionic pair by a strong $\mathrm{N}-\mathrm{H} \cdots \mathrm{I}$ hydrogen bond. In the crystal of $\mathbf{I}$, the tight ionic pairs form hydrogen-bonded zigzag-like chains propagating toward [201] via strong $\mathrm{N}-$ $\mathrm{H}$ - . I hydrogen bonds. The hydrogen-bonded chains are further packed in stacks along [100]. The thermal behaviour of I was studied by different physicochemical methods (thermogravimetry, differential scanning calorimetry and powder diffraction). Differential scanning calorimetry revealed three narrow endothermic peaks at 346, 387 and $525 \mathrm{~K}$, and one broad endothermic peak at $\sim 605 \mathrm{~K}$. The first and second peaks are related to solid-solid phase transitions, while the third and fourth peaks are attributed to the melting and decomposition of $\mathbf{I}$. The enthalpies of the phase transitions at 346 and $387 \mathrm{~K}$ are estimated as 2.60 and $2.75 \mathrm{~kJ} \mathrm{~mol}^{-1}$, respectively. The X-ray powder diffraction data collected at different temperatures indicate the existence of $\mathbf{I}$ as the monoclinic (100-346 K), orthorhombic (346-387 K) and cubic (387-525 K) polymorphic modifications.

\section{Chemical context}

Compounds with the general formula $A B X_{3}$ [where $A$ denotes an organic cation e.g. methylammonium $\left(\mathrm{MA}, \mathrm{CH}_{3} \mathrm{NH}_{3}{ }^{+}\right)$or formamidinium $\left[\mathrm{FA}=\mathrm{CH}\left(\mathrm{NH}_{2}\right)_{2}, \mathrm{CH}_{3} \mathrm{NH}_{3}\right] ; B=\mathrm{Pb}, \mathrm{Sn} ; X=\mathrm{I}$, $\mathrm{Br}, \mathrm{Cl}$ ] belong to a class of hybrid organic-inorganic perovskites and perform as outstanding light harvesters. These compounds gave birth to a new field of photovoltaics perovskite solar cells - when Kojima and co-authors used (MA) $\mathrm{PbI}_{3}$ as a light sensitizer for the first time in dye-sensitized solar cells (DSSCs) in 2009 and showed 3.8\% efficiency (Kojima et al., 2009). Since then, a revolutionary breakthrough has occured in this area and the highest efficiency now has reached $22.1 \%$.

In 2014, the formamidinium cation was proposed to replace methylammonium and the further investigation of (FA) $\mathrm{PbI}_{3}$ disclosed its superiority to (MA) $\mathrm{PbI}_{3}$ (Koh et al., 2014; Pang et al., 2014). In particular, it was found that (FA) $\mathrm{PbI}_{3}$ exhibits higher thermal and moisture stability and has a lower bandgap than (MA) $\mathrm{PbI}_{3}$ which gives a greater capacity for sunlight absorption (Koh et al., 2014; Han et al., 2016). Recently, it was 
shown that the properties of the compounds may be further optimized by tuning the MA/FA ratio and an efficiency of $20.5 \%$ has been reached for a mixed compound ( $\mathrm{Li}$ et al., 2016; Jeon et al., 2015).

The main precursors to obtain (FA) $\mathrm{PbI}_{3}$ are $\mathrm{PbI}_{2}$ and formamidinium iodide (FA)I. Several methods of perovskite synthesis include steps where it can be obtained directly from (FA)I in a crystalline form (Zhou et al., 2015; Leyden et al., 2015). It also appears in a crystalline form and leads to a formation of low-dimensional phases when an excess of it is taken (Xi et al., 2016; Ma et al., 2017). Thus, the understanding of the (FA)I crystal structure gives valuable information for understanding the crystallization of formamidinium-based lead halide perovskites. Knowledge of the (FA)I crystal structure may also be of particular interest for computer simulations of the processes related to the crystallization of these perovskites. Surprisingly, despite the hundreds of papers published over the last several years that have mentioned (FA)I as a major precursor for hybrid lead halide perovskites, its crystal structure has remained unknown so far.<smiles></smiles>

In this work, we investigated the structure of (FA)I (I) and its thermal behaviour by different physico-chemical methods.

\section{Structural commentary}

At a temperature of $100 \mathrm{~K}$, compound $\mathbf{I}$ crystallizes in the monoclinic space group $P 2_{1} / c$. The formamidinium cation adopts a planar symmetrical structure [r.m.s. deviation is $0.002 \AA$, and the $\mathrm{C}-\mathrm{N}$ bond lengths are 1.301 (7) and 1.309 (8) А; Fig. 1]. The iodide anion does not lie within the cation plane, but deviates from it by 0.643 (10) $\AA$. The cation and anion in $\mathbf{I}$ form a tight ionic pair by the strong N1H1A $\cdots$ I1 hydrogen bond (Table 1 and Fig. 1).

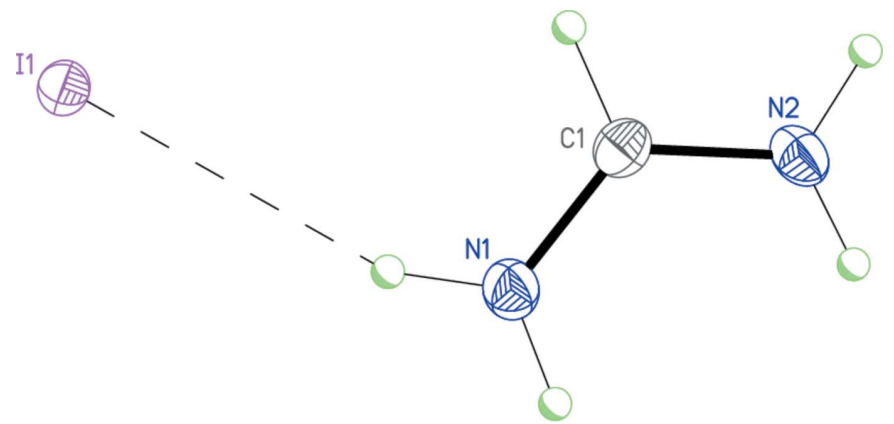

Figure 1

The molecular structure of salt I. Displacement ellipsoids are shown at the $50 \%$ probability level. $\mathrm{H}$ atoms are presented as small spheres of arbitrary radius. Dashed line indicates the intermolecular $\mathrm{N}-\mathrm{H} \cdots \mathrm{I}$ hydrogen bond.
Table 1

Hydrogen-bond geometry $\left(\AA{ }^{\circ}\right)$.

\begin{tabular}{lllll}
\hline$D-\mathrm{H} \cdots A$ & $D-\mathrm{H}$ & $\mathrm{H} \cdots A$ & $D \cdots A$ & $D-\mathrm{H} \cdots A$ \\
\hline $\mathrm{N} 1-\mathrm{H} 1 A \cdots \mathrm{I} 1$ & 0.90 & 2.77 & $3.612(5)$ & 156 \\
$\mathrm{~N} 2-\mathrm{H} 2 A \cdots \mathrm{I} 1^{\mathrm{i}}$ & 0.90 & 2.74 & $3.622(4)$ & 166 \\
\hline
\end{tabular}

Symmetry code: (i) $x-1,-y+\frac{1}{2}, z+\frac{1}{2}$.

In order to understand the thermal behaviour of $\mathbf{I}$ at elevated temperatures, the sample was investigated by TG and DSC methods in the temperature region from 293 to $750 \mathrm{~K}$ at a rate of $5 \mathrm{~K} \mathrm{~min}^{-1}$. The mass loss started from $\sim 520 \mathrm{~K}$ (Fig. 2). Differential scanning calorimetry revealed three narrow endothermic peaks at 346,387 and $525 \mathrm{~K}$, and one broad endothermic peak at $\sim 605 \mathrm{~K}$. The first and the second peaks are related to solid-solid phase transitions, while the third and the fourth peaks are attributed to the melting and decomposition of $\mathbf{I}$. Enthalpy of the phase transitions at 346 and $387 \mathrm{~K}$ are estimated as 2.24 and $2.87 \mathrm{~kJ} \mathrm{~mol}^{-1}$, respectively.

The X-ray powder diffraction data collected at different temperatures confirm the existence of different phases (Fig. 3). At low temperatures, salt $\mathbf{I}$ exists in a monoclinic phase and exhibits a significant change of the parameters with a rise in temperature $(100 \rightarrow 195 \rightarrow 293 \mathrm{~K}$, Fig. 3). A phase existing at $358 \mathrm{~K}$ is indexed in an orthorhombic crystal system [ $a=$ 7.3915 (8) $\AA, b=6.3358$ (8) $\AA, c=5.2391$ (9) $\AA$; $M(20)=25$, $F(20)=45]$. Another high-temperature phase is cubic, exhibiting only a few reflections at $400 \mathrm{~K}[a=5.0571$ (5) $\AA$; $M(13)$ $=126, F(13)=109]$. It seems to be a plastic phase similar to a plastic phase for methylammonium iodide (Ishida et al., 1995; Yamamuro et al., 1992).

\section{Supramolecular features}

In the crystal of $\mathbf{I}$, the tight ionic pairs form hydrogen-bonded zigzag-like chains propagating toward [201] by the strong intermolecular $\mathrm{N} 2-\mathrm{H} 2 A \cdots \mathrm{I} 1{ }^{\mathrm{i}}$ hydrogen bonds (Table 1 and Fig. 4). The hydrogen-bonded chains are further packed in

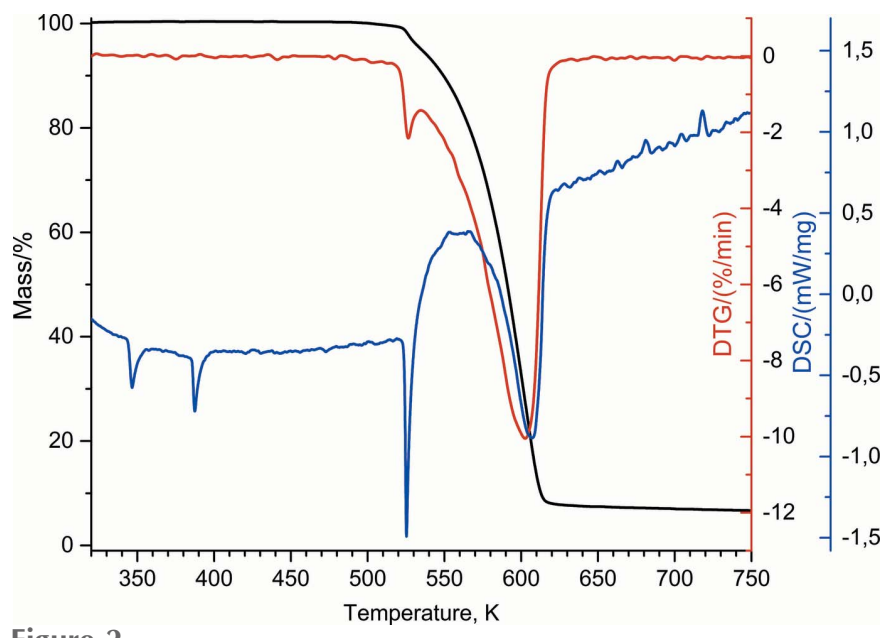

Figure 2

Thermogravimetry and differential scanning calorimetry analyses for $\mathbf{I}$. 


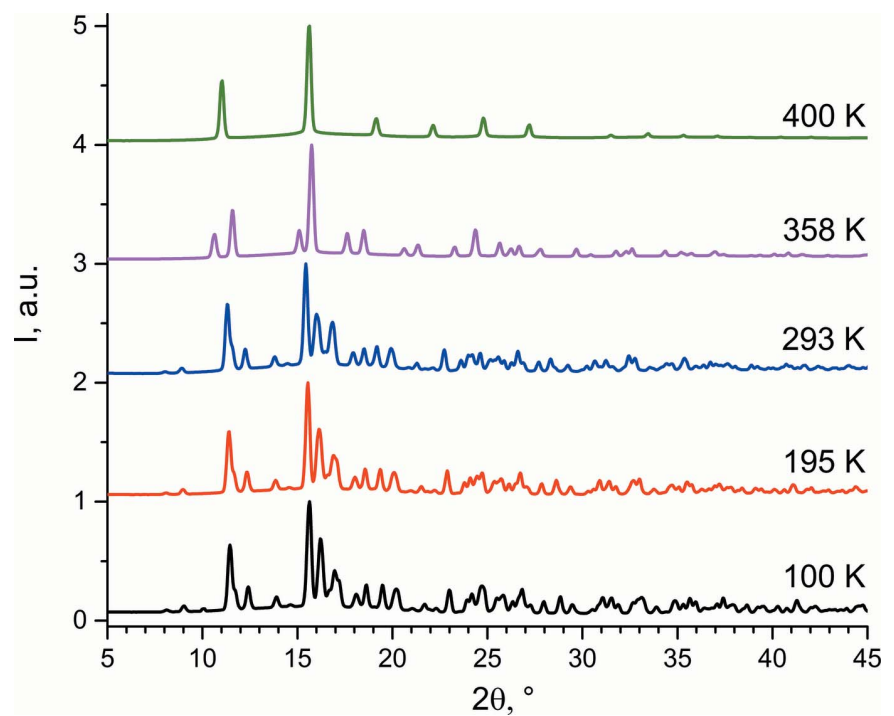

Figure 3

X-ray powder diffraction data for $\mathbf{I}$ at different temperatures.

stacks along [100] (Fig. 4) [symmetry code: (i) $x-1,-y+\frac{1}{2}$, $\left.z+\frac{1}{2}\right]$

\section{Synthesis and crystallization}

Polycrystalline powder of I was purchased from Dyesol and used without further purification. Single crystals suitable for $\mathrm{X}$-ray structural study were obtained by recrystallization from an anhydrous ethanol solution by slow cooling.

\section{Refinement}

Crystal data, data collection and structure refinement details are summarized in Table 2. X-ray diffraction study of $\mathbf{I}$ was

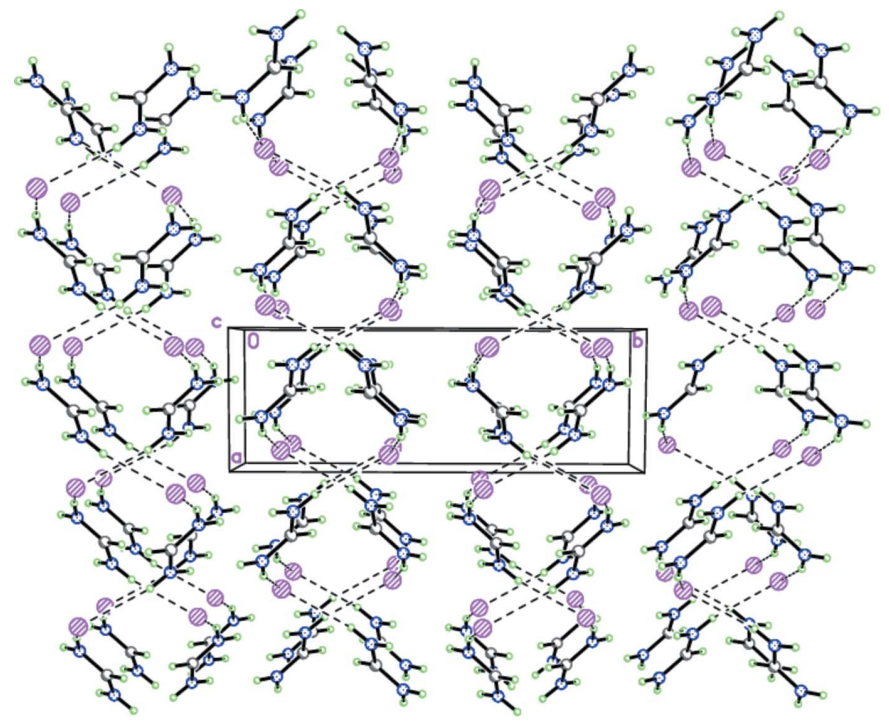

Figure 4

The crystal structure of I demonstrating the hydrogen-bonded zigzag-like chains propagating toward [201] . Dashed lines indicate the intermolecular $\mathrm{N}-\mathrm{H} \cdots \mathrm{I}$ hydrogen bonds.
Table 2

Experimental details.

Crystal data

Chemical formula

$M_{\mathrm{r}}$

Crystal system, space group

Temperature (K)

$a, b, c(\AA)$

$\beta\left({ }^{\circ}\right)$

$V\left(\AA^{3}\right)$

$Z$

Radiation type

$\mu\left(\mathrm{mm}^{-1}\right)$

Crystal size (mm)

$\mathrm{CH}_{5} \mathrm{~N}_{2}^{+} \cdot \mathrm{I}^{-}$

171.97

Monoclinic, $P 2_{1} / c$

100

4.8211 (6), 13.776 (3), 7.0113 (10)

$98.06(3)$

461.06 (14)

Synchrotron, $\lambda=0.96990 \AA$

15.38

$0.06 \times 0.05 \times 0.03$

Data collection

Diffractometer

Rayonix SX165 CCD

Absorption correction

Multi-scan (SCALA; Evans, 2006)

$0.400,0.600$

No. of measured, independent and

$5111,949,894$ observed $[I>2 \sigma(I)]$ reflections

$R_{\text {int }}$

$(\sin \theta / \lambda)_{\max }\left(\AA^{-1}\right)$

0.070

0.642

Refinement

$R\left[F^{2}>2 \sigma\left(F^{2}\right)\right], w R\left(F^{2}\right), S$

No. of reflections

No. of parameters

$\mathrm{H}$-atom treatment

$\Delta \rho_{\max }, \Delta \rho_{\min }\left(\mathrm{e} \AA^{-3}\right)$

$0.039,0.093,1.06$

949

38

$\mathrm{H}$-atom parameters constrained $0.87,-0.91$

Computer programs: Marccd (Doyle, 2011), iMosfm (Battye et al., 2011), SHELXT (Sheldrick, 2015a), SHELXL2014 (Sheldrick, 2015b) and SHELXTL (Sheldrick, 2008).

carried out on the 'Belok' beamline of the National Research Center 'Kurchatov Institute' (Moscow, Russian Federation) using a Rayonix SX165 CCD detector. Reflection intensities measured were corrected for absorption using the Scala (Evans, 2006) program.

The $\mathrm{H}$ atoms of the $\mathrm{NH}_{2}$ groups were localized in the difference Fourier map and refined with fixed positional and isotropic displacement parameters $\left[U_{\text {iso }}(\mathrm{H})=1.2 U_{\text {eq }}(\mathrm{N})\right]$. The $\mathrm{CH}$ hydrogen was placed in a calculated position, with $\mathrm{C}-\mathrm{H}=$ $0.95 \AA$, and refined in the riding model with a fixed isotropic displacement parameter $\left[U_{\text {iso }}(\mathrm{H})=1.2 U_{\mathrm{eq}}(\mathrm{C})\right]$.

\section{Acknowledgements}

This work was supported financially by the Ministry of Education and Science of the Russian Federation (the Agreement number 02.a03.21.0008). AT, AP and EG acknowledge the Russian Foundation for Basic Research for funding the reported study as part of research project No. 1629-03291.

\section{References}

Battye, T. G. G., Kontogiannis, L., Johnson, O., Powell, H. R. \& Leslie, A. G. W. (2011). Acta Cryst. D67, 271-281.

Doyle, R. A. (2011). Marccd software manual. Rayonix L. L. C., Evanston, IL 60201, USA.

Evans, P. (2006). Acta Cryst. D62, 72-82.

Han, Q., Bae, S.-H., Sun, P., Hsieh, Y.-T., Yang, Y. M., Rim, Y. S., Zhao, H., Chen, Q., Shi, W., Li, G. \& Yang, Y. (2016). Adv. Mater. 28, 2253-2258. 
Ishida, H., Maeda, H., Hirano, A., Fujimoto, T., Kubozono, Y., Kashino, S. \& Emura, S. (1995). Z. Naturforsch. Teil A, 50, 14-18.

Jeon, N. J., Noh, J. H., Yang, W. S., Kim, Y. C., Ryu, S., Seo, J. \& Seok, S. I. (2015). Nature, 517, 476-480.

Koh, T. M., Fu, K., Fang, Y., Chen, S., Sum, T. C., Mathews, N., Mhaisalkar, S. G., Boix, P. P. \& Baikie, T. (2014). J. Phys. Chem. C, 118, 16458-16462.

Kojima, A., Teshima, K., Shirai, Y. \& Miyasaka, T. (2009). J. Am. Chem. Soc. 131, 6050-6051.

Leyden, M. R., Lee, M. V., Raga, S. R. \& Qi, Y. (2015). J. Mater. Chem. A3, 16097-16103.

Li, X., Bi, D., Yi, C., Decoppet, J.-D., Luo, J., Zakeeruddin, S. M., Hagfeldt, A. \& Gratzel, M. (2016). Science, 353, 58-62.
Ma, F., Li, J., Li, W., Lin, N., Wang, L. \& Qiao, J. (2017). Chem. Sci. 8, 800-805.

Pang, S., Hu, H., Zhang, J., Lv, S., Yu, Y., Wei, F., Qin, T., Xu, H., Liu, Z. \& Cui, G. (2014). Chem. Mater. 26, 1485-1491.

Sheldrick, G. M. (2008). Acta Cryst. A64, 112-122.

Sheldrick, G. M. (2015a). Acta Cryst. A71, 3-8.

Sheldrick, G. M. (2015b). Acta Cryst. C71, 3-8.

Xi, J., Wu, Z., Xi, K., Dong, H., Xia, B., Lei, T., Yuan, F., Wu, W., Jiao, B. \& Hou, X. (2016). Nano Energy, 26, 438-445.

Yamamuro, O., Matsuo, T., Suga, H., David, W. I. F., Ibberson, R. M. \& Leadbetter, A. J. (1992). Acta Cryst. B48, 329-336.

Zhou, Y., Yang, M., Vasiliev, A. L., Garces, H. F., Zhao, Y., Wang, D., Pang, S., Zhu, K. \& Padture, N. P. (2015). J. Mater. Chem. A, 3, 9249-9256. 


\section{supporting information}

Acta Cryst. (2017). E73, 569-572［https://doi.org/10.1107/S205698901700425X]

Formamidinium iodide: crystal structure and phase transitions

Andrey A. Petrov, Eugene A. Goodilin, Alexey B. Tarasov, Vladimir A. Lazarenko, Pavel V.

Dorovatovskii and Victor N. Khrustalev

Computing details

Data collection: Marccd (Doyle, 2011); cell refinement: iMosflm (Battye et al., 2011); data reduction: iMosflm (Battye et al., 2011); program(s) used to solve structure: SHELXT (Sheldrick, 2015a); program(s) used to refine structure:

SHELXL2014 (Sheldrick, 2015b); molecular graphics: SHELXTL (Sheldrick, 2008); software used to prepare material for publication: SHELXTL (Sheldrick, 2008).

Formamidinium iodide

Crystal data

$\mathrm{CH}_{5} \mathrm{~N}_{2}^{+} \cdot \mathrm{I}^{-}$

$M_{r}=171.97$

Monoclinic, $P 2_{1} / c$

$a=4.8211(6) \AA$

$b=13.776(3) \AA$

$c=7.0113(10) \AA$

$\beta=98.06(3)^{\circ}$

$V=461.06(14) \AA^{3}$

$Z=4$

\section{Data collection}

Rayonix SX165 CCD

diffractometer

$\varphi$ scan

Absorption correction: multi-scan

(Scala; Evans, 2006)

$T_{\min }=0.400, T_{\max }=0.600$

5111 measured reflections

\section{Refinement}

Refinement on $F^{2}$

Least-squares matrix: full

$R\left[F^{2}>2 \sigma\left(F^{2}\right)\right]=0.039$

$w R\left(F^{2}\right)=0.093$

$S=1.06$

949 reflections

38 parameters

0 restraints

Primary atom site location: difference Fourier map

Secondary atom site location: difference Fourier map
$F(000)=312$

$D_{\mathrm{x}}=2.477 \mathrm{Mg} \mathrm{m}^{-3}$

Synchrotron radiation, $\lambda=0.96990 \AA$

Cell parameters from 600 reflections

$\theta=4.0-36.0^{\circ}$

$\mu=15.38 \mathrm{~mm}^{-1}$

$T=100 \mathrm{~K}$

Prism, colourless

$0.06 \times 0.05 \times 0.03 \mathrm{~mm}$

949 independent reflections

894 reflections with $I>2 \sigma(I)$

$R_{\text {int }}=0.070$

$\theta_{\max }=38.5^{\circ}, \theta_{\min }=4.0^{\circ}$

$h=-6 \rightarrow 6$

$k=-17 \rightarrow 17$

$l=-8 \rightarrow 7$

Hydrogen site location: mixed

$\mathrm{H}$-atom parameters constrained

$w=1 /\left[\sigma^{2}\left(F_{\mathrm{o}}^{2}\right)+0.7865 P\right]$

where $P=\left(F_{\mathrm{o}}{ }^{2}+2 F_{\mathrm{c}}{ }^{2}\right) / 3$

$(\Delta / \sigma)_{\max }<0.001$

$\Delta \rho_{\max }=0.87 \mathrm{e} \AA^{-3}$

$\Delta \rho_{\min }=-0.91$ e $\AA^{-3}$

Extinction correction: SHELXL2014

(Sheldrick, 2015b),

$\mathrm{Fc}^{*}=\mathrm{kFc}\left[1+0.001 \mathrm{xFc}^{2} \lambda^{3} / \sin (2 \theta)\right]^{-1 / 4}$

Extinction coefficient: 0.0064 (11) 


\section{Special details}

Geometry. All esds (except the esd in the dihedral angle between two 1.s. planes) are estimated using the full covariance matrix. The cell esds are taken into account individually in the estimation of esds in distances, angles and torsion angles; correlations between esds in cell parameters are only used when they are defined by crystal symmetry. An approximate (isotropic) treatment of cell esds is used for estimating esds involving l.s. planes.

Fractional atomic coordinates and isotropic or equivalent isotropic displacement parameters $\left(\AA^{2}\right)$

\begin{tabular}{lllll}
\hline & $x$ & $y$ & $z$ & $U_{\text {iso }} * U_{\text {eq }}$ \\
\hline I1 & $0.86658(6)$ & $0.38577(2)$ & $0.20022(5)$ & $0.0218(2)$ \\
N1 & $0.6120(9)$ & $0.4171(3)$ & $0.6569(7)$ & $0.0250(10)$ \\
H1A & 0.7250 & 0.4174 & 0.5650 & $0.030^{*}$ \\
H1B & 0.6251 & 0.4648 & 0.7454 & $0.030^{*}$ \\
N2 & $0.2540(9)$ & $0.3389(3)$ & $0.7860(7)$ & $0.0254(11)$ \\
H2A & 0.1352 & 0.2882 & 0.7776 & $0.030^{*}$ \\
H2B & 0.2515 & 0.3832 & 0.8801 & $0.030^{*}$ \\
C1 & $0.4296(11)$ & $0.3478(4)$ & $0.6606(8)$ & $0.0227(11)$ \\
H1 & 0.4233 & 0.2994 & 0.5637 & $0.027^{*}$ \\
\hline
\end{tabular}

Atomic displacement parameters $\left(\AA^{2}\right)$

\begin{tabular}{lllllll}
\hline & $U^{11}$ & $U^{22}$ & $U^{33}$ & $U^{12}$ & $U^{13}$ & $U^{23}$ \\
\hline $\mathrm{I} 1$ & $0.0230(3)$ & $0.0215(3)$ & $0.0217(4)$ & $0.00012(9)$ & $0.0054(2)$ & $-0.00041(10)$ \\
$\mathrm{N} 1$ & $0.022(2)$ & $0.030(2)$ & $0.023(3)$ & $-0.0030(18)$ & $0.0030(19)$ & $0.000(2)$ \\
$\mathrm{N} 2$ & $0.021(2)$ & $0.022(2)$ & $0.034(3)$ & $-0.0020(17)$ & $0.008(2)$ & $0.0011(19)$ \\
$\mathrm{C} 1$ & $0.023(2)$ & $0.026(3)$ & $0.019(3)$ & $0.002(2)$ & $0.001(2)$ & $0.000(2)$ \\
\hline
\end{tabular}

Geometric parameters $\left(\AA,{ }^{\circ}\right)$

\begin{tabular}{llll}
\hline $\mathrm{N} 1-\mathrm{C} 1$ & $1.301(7)$ & $\mathrm{N} 2-\mathrm{H} 2 \mathrm{~A}$ & 0.8999 \\
$\mathrm{~N} 1-\mathrm{H} 1 \mathrm{~A}$ & 0.9001 & $\mathrm{~N} 2-\mathrm{H} 2 \mathrm{~B}$ & 0.9000 \\
$\mathrm{~N} 1-\mathrm{H} 1 \mathrm{~B}$ & 0.9001 & $\mathrm{C} 1-\mathrm{H} 1$ & 0.9500 \\
$\mathrm{~N} 2-\mathrm{C} 1$ & $1.309(8)$ & & \\
& & & 120.0 \\
$\mathrm{C} 1-\mathrm{N} 1-\mathrm{H} 1 \mathrm{~A}$ & 119.7 & $\mathrm{~N} 1-\mathrm{C} 1-\mathrm{N} 2-\mathrm{N} 2 \mathrm{~B}$ & $125.8(5)$ \\
$\mathrm{C} 1-\mathrm{N} 1-\mathrm{H} 1 \mathrm{~B}$ & 120.3 & $\mathrm{~N} 1-\mathrm{C} 1-\mathrm{H} 1$ & 117.1 \\
$\mathrm{H} 1 \mathrm{~A}-\mathrm{N} 1-\mathrm{H} 1 \mathrm{~B}$ & 120.0 & $\mathrm{~N} 2-\mathrm{C} 1-\mathrm{H} 1$ & 117.1 \\
$\mathrm{C} 1-\mathrm{N} 2-\mathrm{H} 2 \mathrm{~A}$ & 119.7 & & \\
$\mathrm{C} 1-\mathrm{N} 2-\mathrm{H} 2 \mathrm{~B}$ & 120.3 & & \\
\hline
\end{tabular}

Hydrogen-bond geometry $\left(A,{ }^{\circ}\right)$

\begin{tabular}{lllll}
\hline$D-\mathrm{H} \cdots A$ & $D-\mathrm{H}$ & $\mathrm{H} \cdots A$ & $D \cdots A$ & $D-\mathrm{H} \cdots A$ \\
\hline $\mathrm{N} 1-\mathrm{H} 1 A \cdots \mathrm{I} 1$ & 0.90 & 2.77 & $3.612(5)$ & 156 \\
$\mathrm{~N} 2-\mathrm{H} 2 A \cdots \mathrm{I} 1^{\mathrm{i}}$ & 0.90 & 2.74 & $3.622(4)$ & 166 \\
\hline
\end{tabular}

Symmetry code: (i) $x-1,-y+1 / 2, z+1 / 2$. 